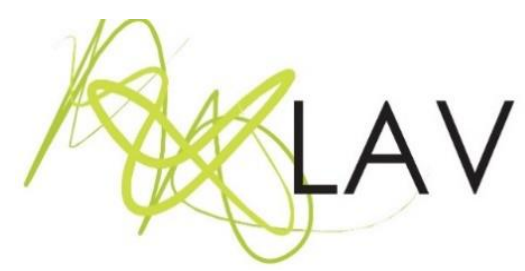

\title{
Estudo, pesquisa e produção do conhecimento no horizonte hermenêutico- filosófico
}

Study, research and production of knowledge in the hermeneutic-philosophical horizon

\author{
Maria Regina Regina Johann ${ }^{i}$
}

Universidade Regional do Noroeste do Rio Grande do Sul

"Pesquisa é a participação da gente na totalidade".

(Paulo R. Schneider, 2018)

\begin{abstract}
Resumo
A hermenêutica filosófica argumenta a favor da linguagem e do pensamento no horizonte de sentidos construídos por uma consciência histórica. Evidencia o diálogo como o modo humano de compreender e autocompreender e destaca a pergunta como o elemento fundamental do conhecer. Este ensaio recorre a estes fundamentos para apresentar a noção de pesquisa como a tradição histórica que se atualiza na fusão de horizonte de sentidos de cada pesquisador. Apresenta a noção de consciência histórica como o âmbito no qual realizamos nossa compreensão de mundo a partir dos pré-conceitos herdados. Enfatiza o diálogo e o conhecimento como âmbitos da experiência autêntica e desenvolve a noção de projeto prévio de compreensão como uma dimensão estruturante do acesso ao texto. Permite o entendimento de que a pesquisa, constrangida pela lógica do produtivismo acadêmico, restringe a experiência de acesso à alteridade do texto e a possibilidade de compreensão e autotransformação.
\end{abstract}

Palavras-chave: consciência histórica, diálogo, abertura, outro, conhecimento.

\begin{abstract}
Philosophical hermeneutics argues in favor of language and thought in the horizon of meanings constructed by a historical consciousness. It evidences the dialogue as the human way of understanding and self-understanding and highlights the question as the fundamental element of knowledge. This essay draws on these grounds to present the notion of research as the historical tradition that is updated in the fusion of the horizon of senses of each researcher. It presents the notion of historical consciousness as the framework in which we realize our understanding of the world from inherited preconceptions. It emphasizes dialogue and knowledge as areas of authentic experience and develops the notion of the prior project of understanding as a structuring dimension of access to the text. It allows the understanding that research, constrained by the logic of academic productivism, restricts the experience of access to alterity of the text and the possibility of understanding and self-transformation.
\end{abstract}

Keywords: historical consciousness, dialogue, openness, other, knowledge. 


\section{A pesquisa no horizonte da hermenêutica filosófica: consciência histórica, diálogo e abertura}

A hermenêutica filosófica recolocou o dilema da compreensão, assumindo-a como algo que está sempre na dependência da linguagem, da intersubjetividade e da historicidade, ou seja, de uma tradição de mundo humano. Fez isso tomando a arte como referência ao evidenciar que a sua verdade não se apresenta do mesmo modo que a verdade da ciência, mas que nem por isso é menos relevante no conjunto de tradições históricas que configuram o mundo comum. Desse modo, introduziu uma questão radical sobre a interpretação na medida em que alertou para a validade de verdades que se apresentam também ao modo poético e estético. Essa ideia é uma chave que contribui para pensar a pesquisa quando perguntamos sobre a relação entre pesquisador e texto/obra, sobre a validade daquilo que se apresenta no horizonte da pesquisa e em que medida acolhemos o outro que nos vem no horizonte (da alteridade) aberto pelo estudo/pesquisa.

Em Verdade e método (1999), Gadamer trata do método como algo que contorna a verdade e mostra que não se trata de desqualificar o modo como a ciência constrói suas respostas, mas de admitir que elas também sejam construções históricas, estando, de certo modo, condicionadas a uma visão de história, de ciência, ao olhar e o recorte que se faz do objeto e, ainda, a disposição do pesquisador diante daquilo se apresenta no processo de pesquisa. A constatação de que as objetivações da ciência estão na dependência da linguagem, do método e do contexto histórico, exige, por parte da comunidade científica, o aceite de que suas verdades dependem de uma comunidade argumentativa, ou seja, de um acordo na tradição da linguagem. Desse modo, a perspectiva hermenêutica filosófica permite compreender que não é possível dizer algo de modo absoluto e conclui, por isso, que as verdades estão na dependência dos acordos da linguagem e, ainda, que elas necessitam ser trazidas ao horizonte de cada um e assumidas na intransparência da linguagem $^{1}$ como verdades acordadas histórica e intersubjetivamente e, portanto, provisórias.

Diante do exposto, este ensaio destaca as contribuições do pensamento gadameriano para pensar o estudo e a pesquisa como um modo de acesso à tradição histórica que se atualiza no horizonte de sentidos de cada pesquisador e se convalida em uma comunidade científica que compartilha uma tradição de área mediante diálogos legitimados histórica e intersubjetivamente. Para tanto, estrutura o texto em três tópicos que se inter-relacionam. O primeiro, trata da noção de consciência histórica como o âmbito no qual realizamos

\footnotetext{
1 Esta noção de que a linguagem nunca esgota o dizer, pois o mesmo se renova em cada sujeito que diz novamente alguma coisa, tem em Gadamer sua inspiração e é desenvolvida por Fensterseifer e Boufleuer, no texto Conhecimento e crítica: em busca de uma fundamentação não metafisica (2014), publicado no livro Teoria, crítica, filosofia e educação. Homenagem a Pedro Goergen.
} 
nossa compreensão de mundo a partir dos pré-conceitos que herdamos ao nos inserir no mundo humano. O segundo, destaca o diálogo como nosso modo ontológico de acesso ao conhecimento de mundo e destaca a pergunta como um elemento próprio do conhecer. Nisso, evidencia que a pergunta é o modo como nos abrimos ao outro que nos vem na alteridade do novo, daquilo que desejamos saber. Na sequência, apresenta a ideia gadameriana de projeto prévio de compreensão como uma dimensão estruturante da pesquisa de caráter hermenêutico-filosófico, a qual afirma que a compreensão requer a participação em uma comunidade de linguagem e a capacidade de formular uma pergunta. Por fim, destaca as contribuições da hermenêutica filosófica para pensar o sentido do estudar e do pesquisar e tensiona esse aspecto à lógica contemporânea do produtivismo acadêmico que, por vezes, limita as possibilidades da experiência do estudo e da pesquisa como um tempo/espaço de abertura, alteridade e autotransformação. Ao fazer isso, aponta algumas dessas razões para pensar a educação.

\section{Consciência histórica: a tradição como âmbito estruturante dos nossos pré- conceitos}

Levar em consideração a noção de consciência histórica é o mesmo que compreender que somos seres na e da história, que nossos atos e pensamentos estão encharcados dela, uma vez que estamos, a todo momento, recebendo os recados da tradição histórica; nesse sentido, não há humano que não seja atravessado pela história, nascido na sua tradição. Esta é a nossa condição de ser-no-mundo (humano): portamos a consciência da finitude e, no entanto, somos também capazes de pensar a própria transcendência, pois, quando fazemos filosofia e arte, saímos do ordinário e acessamos ao extraordinário. A consciência da nossa finitude é uma consciência histórica que permite olhar o que já foi e seguir propondo intersubjetivamente um vir a ser. Isso significa dizer que a nossa subjetividade se faz intersubjetivamente num efeito (evento) histórico, coletivo, mas, também, particular, em que participamos da totalidade que é o mundo. Já a consciência da transcendência é a nossa capacidade humana instituidora de sentidos, estado que nos permite transcender a objetividade da coisa/fato, a possibilidade individual de ressignificar a tradição/historicidade, de criar e inscrever no mundo algo, como a exemplo da arte. ${ }^{2}$

No horizonte de um estudo ${ }^{3}$ (aqui entendido como a dedicação a um pensador, obra ou tema sem a intenção de prospectar um trabalho acadêmico ao modo de uma dissertação ou tese) e de uma pesquisa (o investimento com pretensão de se materializar em trabalho

\footnotetext{
2 O tema apresentado neste texto já foi, em certa medida, desenvolvido por Johann e Fensterseifer (2018), no artigo "o inflacionamento informativo e o deflacionamento compreensivo", publicado na obra Educação em debate: cercanias da pesquisa, organizada por Fuchs, Schwengber e Schutz.

${ }^{3}$ Jorge Larrosa certa vez comentou: "[...] hoje não estudamos mais, fazemos investigações (pesquisa) " (fonte oral, 2002).
} 
acadêmico que passa pelo crivo de uma comunidade científica), somos mobilizados por uma ideia, pergunta, hipótese. É esse movimento inicial que fomenta nosso pensar em direção a uma nova possibilidade de compreensão, de relação e expressão de algo, denominado, por Gadamer, de pré-conceitos: aquilo que já temos e nos permite realizar a empreitada do estudo e pesquisa. Isso significa que, ao sermos inseridos numa tradição e numa cultura, vamos adquirindo padrões, valores, noções e saberes que se configuram em nossa bagagem pessoal e social: essa bagagem são as referências que nos permitem compreender e interpretar. Sem pré-conceitos não conseguimos nos inserir em uma comunidade de sentidos, pois é como se nos faltasse a linguagem daquela comunidade. Desse modo, os pré-conceitos podem ser traduzidos por tradição: a tradição herdada nos habilita à compreensão. Nossos pré-conceitos se expandem e se atualizam na medida em que entramos em contato com outros pré-conceitos, encontrados em diferentes modos de expressão, como os textos e as obras de arte (JOHANN, 2015).

Fazer pesquisa, nesse horizonte de compreensão, é refazer caminhos instituindo o novo, levando em consideração a experiência de conhecimento da qual somos capazes de viver (fazer), de dentro da tradição histórica, funcionando como uma grande biblioteca

[...] que guarda as referências que permitem a uma cultura, a uma civilização, decifrar, ler, interpretar, traduzir as várias manifestações, as múltiplas e diversificadas concreções da linguagem (WADDINGTON, 2002, p. 175).

Tomando a tradição ao modo de uma bagagem cultural, podemos dizer que determinada pesquisa ou estudo se coloca para cada um de nós de dentro de uma (interpretação da) tradição, que fornece dados, hipóteses, métodos e referências conceituais para pensar. Nisso, a própria noção de pesquisa é afetada pela historicidade (da sua tradição) da ciência, do conhecimento, da filosofia, residindo aí a sua potencialidade propositiva, crítica e reconstrutiva. Nessa chave de leitura, a emergência do "novo" é um fenômeno hermenêutico histórico e filosófico, porque nasce da capacidade interpretativa e criativa do sujeito (subjetividade), ao modo como traduz a história (objetividade) em seu horizonte de sentidos (intersubjetividade). Assim, aquilo que sabemos é uma compreensão constituída historicamente (coletivamente) a partir da capacidade linguística, simbólica, cognitiva, reflexiva e criativa do humano. Esclarecemos nossa compreensão acerca da noção de consciência histórica citando a passagem de Gadamer em Verdade e método:

Ser histórico quer dizer não se esgotar nunca no saber-se. Todo saber-se procede de um dado histórico prévio, que chamamos, com Hegel, "substância", porque suporta toda opinião e comportamento subjetivo e, com isso, prefigura e delimita toda possibilidade de 
compreender uma tradição em sua alteridade histórica (GADAMER, 1999, p. 451).

Essa consciência histórica é a percepção de que não estamos diante de uma situação, mas, sim, já nos encontramos nela, participando dela. Estamos diante de uma tradição que queremos compreender; no entanto, essa tradição também está em nós. Gadamer (1999) denomina essa condição de situação hermenêutica, sendo ela uma situação que desejamos iluminar com nossa reflexão; contudo, por essa reflexão se dar num horizonte histórico efeitual $^{4}$, ela fica impossibilitada de um esclarecimento total, ou de uma iluminação absoluta, uma vez que sempre fica algo que ainda não foi dito, que se apresenta no horizonte de sentido de cada intérprete, que a cada vez perfaz o caminho da tradição histórica a seu modo, atualizando sentidos 5 . De acordo com Gadamer (1999), essa situação hermenêutica da verdade não necessita ser vista como um problema, mas, sim, como a condição sempre aberta - vivificada pelo diálogo -, instaurada pela pergunta que cada um imprime a partir da intersubjetividade dialógica.

A não pretensão de totalidade da interpretação se alicerça, na perspectiva hermenêuticofilosófica, na virada do texto para a autocompreensão do intérprete. Isso não significa que a interpretação seja a produção de um sujeito soberano, mas sim a participação em um acontecimento compreensivo.

Esta guinada filosófica da essencialidade para a historicidade do sujeito coloca exigências específicas à pesquisa educacional e à própria pesquisa bibliográfica em especial, permitindo pensar a relação entre intérprete e texto de maneira aberta, na perspectiva autoformativa do sujeito pesquisador (DALBOSCO, 2017, p. 2-3).

Esse paradigma leva em consideração que a interpretação se dá nos contornos da linguagem, dos sentidos históricos e da compreensão subjetiva como algo situado na mundanidade do homem. Dessa ideia, entendemos que tanto o texto quanto o sujeito estão em uma situação hermenêutica, afetando-se mutuamente.

Tomar a linguagem como o medium da experiência hermenêutica significa que a compreensão sobre alguma coisa não está exclusivamente no sujeito e, tampouco, no objeto, mas na fusão de seus horizontes de sentidos. Para compreender, é preciso pôr-se de acordo sobre as coisas deslocando-se em sua direção; ${ }^{6}$ assim, "[...] a linguagem é o

\footnotetext{
${ }^{4}$ Para Gadamer (1999, p. 448) "um pensamento verdadeiramente histórico tem de pensar, ao mesmo tempo, a sua própria historicidade. [...] Um verdadeiro objeto histórico não é um objeto, mas é a unidade de um e de outro, uma relação na qual permanece tanto a realidade da história como a realidade do compreender histórico". 5 Do ponto de vista da hermenêutica filosófica, "sentido é, como pode nos ensinar a linguagem, sentido de direção. Vê-se em uma direção, assim como o ponteiro do relógio, que gira em um sentido determinado. Assim nós todos tomamos, sempre que algo nos é dito, a direção que aponta para o sentido" (ROHDEN, 2002, p. 195).

${ }^{6}$ Para Gadamer (1999, p. 599) "[...] a experiência de sentido, que ocorre desse modo na compreensão, encerra sempre um momento de aplicação. Percebemos agora que todo este processo é um processo linguístico".
} 
meio em que se realiza o acordo dos interlocutores e o entendimento sobre a coisa" (GADAMER, 1999, p. 559-560). A natureza da linguagem nos coloca em direção de alguém, uma vez que é próprio dela o esquecimento de si e a busca do outro em um falar compartilhado e que permite nos reconhecermos em nossa humanidade histórica. Aqui já temos um dos elementos-chave para pensar a pesquisa, ou seja, a disposição do intérprete em ouvir o texto e levar em consideração seus recados, o que não significa submeter-se ao texto, mas abrir-se a ele 7 . Na perspectiva hermenêutico-filosófica,

a 'observação' transforma-se em escuta e saber observar significa saber escutar, [...] torna-se parte indispensável da 'boa' formação do sujeito pesquisador sua abertura para ouvir o outro. Abertura e escuta são dois núcleos fundantes de sua formação (DALBOSCO, 2014, p. 20).

Nessa abertura reside, de acordo com Gadamer (1999), a possibilidade do acontecer da experiência autêntica que é originária da abertura, ou seja, da emergência do novo que a pergunta permite instituir.

\section{Diálogo e pergunta: abertura ao outro como um âmbito da experiência autêntica} Linguagem e diálogo estão um para o outro, a interdependência entre ambos é que assegura a sua própria vida. O diálogo (vivo) nada mais é do que "[...] propor alguma coisa e seguir suas implicações" (GADAMER, 2004, p. 242). Quem se abre ao diálogo se abre à experiência autêntica do acontecer da verdade porque o diálogo pressupõe o eu e o outro, a pergunta e as possíveis respostas geradas no âmbito da reflexão. Nesse horizonte, diálogo também é "[...] o modo como textos passados, informações passadas, ou os produtos da capacidade artística da humanidade nos alcançam" (GADAMER, 2004, p. 171) e, inclusive, o modo como acessamos a verdade, pois ela "[...] não é um método, mas simplesmente aquilo que acontece no diálogo. [...] Se todo entendimento é diálogo, então é tanto uma conversa com o passado quanto com o futuro" (LAWN, 2007, p. 13).

O diálogo, como uma estrutura ou método de chegar à verdade consensuada, é recuperado, por Gadamer, da tradição dialógica grega, pois o essencial sempre é isto: o método não define a verdade, não a esgota; a relação entre verdade e método não é de exclusão, mas de tensão complementar. Isso permite desvencilhar a verdade de uma visão e entendimento científicos e abrir as possibilidades de acesso a ela (ROHDEN, 2012).

No horizonte da hermenêutica filosófica, é pelo diálogo vivo que a verdade ocorre entre os homens; é na força viva do diálogo que compreendemos e nos autocompreendemos. Por

\footnotetext{
${ }^{7}$ Gadamer (1999) usa a expressão ouvidos de mercador para aquele que já se coloca, de antemão, como estando certo e não se permite escutar o outro (texto, obra, pessoa).
} 
isso, o conceito de circularidade heideggeriano inspirou Gadamer a pensar a estrutura do diálogo como âmbito de entendimento entre os homens, que requer uma estrutura prévia de compreensão, pois nenhuma linguagem conceitual significa um feitiço irremediável; o pensador se confia à linguagem em diálogo com outros pensadores (GADAMER, 2004). A noção de verdade situada na historicidade do mundo da vida admite que seja na finitude da linguagem que a verdade é produzida. É desse entendimento de verdade que o diálogo se destaca como uma estrutura compreensiva, porque é dialogando com o outro, aberto às suas questões, que se chega a um entendimento sobre algo. Emerge daí a consideração gadameriana ao círculo dialógico como uma estrutura universal de chegar à verdade; porém, agora, uma verdade acordada.

Nessa perspectiva, a abertura é inerente ao modo de ser do diálogo, uma vez que, sem disposição para ouvir o outro, ele não acontece. Dessa forma, todo diálogo vivo instaura a reflexão, que nos vem como pergunta e nos mobiliza a compreender (JOHANN, 2015). Nisso, evidenciamos que a pergunta é a condição básica da interpretação, uma vez que ela movimenta o pensamento pelo diálogo que instaura. A possibilidade aberta e transformadora do diálogo ultrapassa o ponto de partida da subjetividade do sujeito, pois "onde um diálogo teve êxito ficou algo para nós e em nós que nos transformou" (GADAMER, 2004 , p. 247) porque ele exige que se saiba ver o outro como outro.

Do contrário, diante da incapacidade de ouvir o outro, podemos induzir as pesquisas a responderem, exclusivamente, aquilo que o método determina, fixar uma vertente teórica ou filosófica, ou o que o pesquisador insiste em ser sua (tese) hipótese. Na contramão disso, a aposta no diálogo em favor da universalidade da linguagem nada mais é do que chamar a atenção para a necessidade de abertura ao outro que nos vem durante o estudo e a pesquisa, ao modo de textos, obras, conversas, documentários, estudos, enfim, através de diferentes outros que nos chegam quando desejamos conhecer algo.

Dalbosco corrobora essa noção ao destacar o estranhamento e o distanciamento como posturas investigativas, mencionando que

estranhar-se a si mesmo e compreender o estranho exige o exercício paciente da escuta, que leva o sujeito pesquisador a não emitir juízos apressados a respeito das mensagens de seus interlocutores (DALBOSCO, 2017, p. 5).

Isso permite afirmar que quem está disposto a compreender necessita abrir-se ao texto, deixar-se atravessar por ele, para, então, convalidar suas ideias. Isso, contudo, não significa submissão ao texto, mas considerar que ali poderá ter algo importante para nós!

Revista Digital do LAV - Santa Maria - vol. 11, n. 3, p. 82 - 97 - set./dez. 2018 ISSN 1983 - 7348 http://dx.doi.org/10.5902/1983734832832997 
Ao apostar na abertura do diálogo como uma dimensão ontológica da formação humana aquela que nos permitiu produzir acordos e saberes no mundo da vida -, Gadamer permite pensar que o conhecimento construído no mundo da vida é tão verdadeiro quanto aquele que se constrói na comunidade científica, uma vez que ambas são comunidades de diálogos legítimas, cada qual com suas particularidades.

Frente a uma hermenêutica que se orienta no diálogo socrático não se deve objetar que somente a doxa não é um saber, que o acordo aparente no qual vivemos e desde o qual falamos não é um verdadeiro acordo. O próprio descobrimento do aparente, como faz o diálogo socrático, todavia, se realiza no elemento próprio da linguagem (GADAMER, 2004, p. 567).

Nesse horizonte, a natureza do diálogo assegura infinitas possibilidades de compreensão, inclusive a compreensão da não compreensão, uma vez que o que nos é comum em nossa humanidade é justamente a

[...] constituição de nosso mundo da vida construída na linguagem. Qualquer tentativa de denunciar as degradações do entendimento entre os seres humanos mediante a reflexão crítica e a argumentação confirma essa nota comum (GADAMER, 2004, p. 567).

Por isso a aposta de que no jogo dialógico seja possível encontrar a linguagem comum que permita aos humanos entenderem seu mundo e nele se entenderem.

Enredados na linguagem, podemos viver a experiência autêntica. Aquele algo que nos acontece, que se dá como um afetamento, que desloca nosso ponto de vista, permitindo estar diante de uma novidade, daquele instante que nosso olhar estranha e, ao mesmo tempo, percebe cognitiva, estética e sensivelmente. Essa experiência autêntica está na dependência da entrega e da abertura, momento em que podemos refazer um caminho como um processo pré-ontológico de escavar e nos perguntar por algo (muitas das vezes óbvio). Para Gadamer, a abertura é o núcleo da experiência hermenêutica, ela assume a forma estrutural da pergunta, assim, pergunta e abertura são complementaridades geradoras da possibilidade da experiência autêntica, aquele instante em que somos convocados a sair do ordinário para o extraordinário.

\section{A compreensão requer um projeto prévio de compreensão: algumas considerações acerca da ideia de aplicação}

Um caminho hermenêutico exige, segundo Gadamer (1999), um projeto, pois aquele que quer compreender algo realiza um projeto prévio de compreensão, no qual a opinião 
prévia $^{8}$, a visão prévia e a concepção prévia do pesquisador confrontam-se com o que se pretende compreender e, ainda, se atualizam e se reelaboram permanentemente. Por isso, estar aberto à escuta do outro é próprio do diálogo vivo, o que, pela natureza de abertura e ocultamento da linguagem, nos obriga a ultrapassar as dimensões da lógica enunciativa e alcançar horizontes mais amplos (JOHANN, 2015). Assim, no percurso de estudo e/ou pesquisa, experimentamos aquilo que Gadamer afirma ser o pôr-se de acordo sobre as coisas deslocando-se em sua direção, pois, por meio dos textos, obras, escutas, diálogos, encontramos diferentes autores, conceitos, ideias, filosofias que se constituem em interlocutores acerca daquilo que almejamos conhecer melhor.

A própria terminologia hermenêutica já se coloca como uma filosofia calcada no diálogo, pois Hermes traz e também leva mensagens! Para fazê-lo, necessita portar a linguagem, escutar, mas, fundamentalmente, compreender o que deverá transmitir. Hermes é um tradutor que não levará literalmente o que foi dito, mas traduzirá, ao seu modo, o que deve dizer.

Essa metáfora ajuda a explicar o que Gadamer entende por empreender um projeto de compreensão prévia: ao estudar um texto, mobilizamos nossos pré-conceitos em busca dos sentidos expressos na obra. Para tanto, necessitamos de um projeto de compreensão prévia, significando que precisamos dominar os códigos, a linguagem: esse é o pressuposto básico. Portando a linguagem entramos no texto em busca dos sentidos do autor, não para desvelar o que ele quis dizer, mas para considerar o que disse, em que tempo e contexto histórico disse, e como diria, caso pudesse dizê-lo atualmente (SCHMIDT, 2013). Desse modo, estamos entendendo a metáfora gadameriana de fusão de horizontes de sentidos: é como se Hermes, ao ouvir a mensagem, tivesse que atualizá-la para que fosse compreendida. Atualizá-la, portanto, significa incorporar aquilo que o tempo presente já evidenciou.

A compreensão, então, requer do intérprete três dimensões que se complementam: a primeira delas é a capacidade de considerar a objetividade/plasticidade do texto/obra (a matéria, a mensagem, a linguagem); a segunda é a disposição do intérprete em rever seus pré-conceitos, permitir que os pré-conceitos ingênuos sejam modificados ou atualizados, entendendo que a historicidade exerce um efeito sobre a nossa compreensão; e a terceira, ser capaz de atualizar o texto, considerando sua tradição histórica e trazendo-o para o horizonte de sentidos do intérprete, algo como se o autor estivesse escrevendo hoje o que

\footnotetext{
${ }^{8}$ A opinião prévia pode ser entendida como os pré-conceitos que nos permitem formular um projeto prévio.
} 
ele possivelmente consideraria. Por fim, Gadamer considera relevante, no ato interpretativo, levarmos em consideração duas perguntas que se inter-relacionam:

A primeira pergunta é colocada ao intérprete pelo texto histórico. Alguma coisa do passado releva uma pergunta para mim e é por isso que estou interessado em compreender o que o texto tem a dizer. Para responder esta primeira pergunta "precisamos tentar reconstruir a pergunta à qual o texto tradicional é a resposta" (VM: 374). [...] portanto, "uma pergunta reconstruída nunca pode ficar dentro de seu horizonte original" (VM: 374). O intérprete precisa ir além do horizonte histórico da pergunta à qual o texto era uma resposta porque ele não pode ignorar o que ele sabe e o autor não sabia (SCHMIDT, 2013, p. 164).

Se bem entendemos, essa seria, em linhas gerais, a ideia gadameriana de aplicação de um projeto de compreensão. Isso não significa que há um método para interpretar, mas, sim, de que o intérprete deve levar em consideração o que é dito na obra e se abra aos sentidos possíveis que o texto possibilita, numa disposição efetiva de reconstrução de sentidos, dos seus próprios sentidos e verdades, num horizonte que acolhe o outro como outro, que aceita a alteridade que vem do e no texto, disposto a viver uma experiência de autotransformação. Quando o pesquisador se permite afetar-se pelo texto, ele pode viver uma experiência de autoeducação; nisso vemos atualizado próprio sentido do estudo e da pesquisa.

\section{Estudar e pesquisar como uma experiência (autêntica) de acesso ao conhecimento: desafio para pensar a escrita acadêmica em contextos de produtividade}

A tradição pode ser entendida como uma fonte possível de pré-conceitos legítimos que se expressam em obras materiais e imateriais ${ }^{9}$. Nessa direção, os textos tradicionais, os clássicos, podem nos ensinar coisas legítimas (SCHMIDT, 2013). Eles podem atualizar nosso pensamento na medida em que permitem confrontar a tradição com o novo, instante em que, muitas das vezes, estranhamos o óbvio. Nesse sentido, a compreensão atualiza a tradição.

Considerando a epígrafe apresentada no texto, estamos entendo que a pesquisa é a nossa participação na totalidade, ao modo como recebemos os recados da tradição de uma determinada área de conhecimento e traduzimos seus sentidos, como dizemos algo em perspectiva própria. Nessa direção, a ciência é o acontecimento participativo na configuração da totalidade que é o mundo humano (SCHNEIDER, 2018). Trazendo essa noção em direção à hermenêutica filosófica, entendemos que, para uma experiência

\footnotetext{
${ }^{9}$ Alguns exemplos de obras materiais: livro, quadro, escultura, fotografia; já de obras imateriais, podemos indicar a festa, a música, o jogo, o mito, os rituais.
} 
autêntica de acesso à verdade, devemos nos abrir ao texto, encontrar (interpretar) seus recados e traduzi-los a partir dos nossos horizontes de compreensão, participando, desse modo, na construção do conhecimento e na atualização das ideias. Isso significa que a objetividade do texto/obra não esgota as possibilidades de novos sentidos, por isso sempre é possível refazer um percurso investigativo e escavar novos sentidos, como um cultivo na nossa própria aprendizagem.

Nessa perspectiva, a experiência autêntica de acesso ao conhecimento (verdade) que o estudo e a pesquisa podem gerar assume um caráter transformador e autopoético, pois a experiência como experiência (GADAMER, 1998) permite uma autotransformação: algo compreendido é algo in-corporado, prendido junto a mim, significa que não posso descompreender! Algo se passa comigo, isso é arrebatador!

No âmbito do estudo e da pesquisa acadêmica, investir no projeto prévio de compreensão é trabalhar na tradução do texto, na tradutibilidade da ideia, do pensamento e, com isso, deixar o texto falar, entrando em diálogo conosco. Nesse processo hermenêutico-filosófico, a consciência da tradição se realiza na linguagem viva do diálogo, instante em que percebemos que o que somos é uma construção histórica. Isso significa que, sem a abertura ao outro que o estudo nos permite, não estudamos e nem pesquisamos, mas, sim, replicamos discursos, copiamos ideias, requentamos textos, constituímos grupos de produção (quase em série) e, assim, também fomentamos a lógica produtivista que apelidamos de lattização da pesquisa.

Relacionando esse tema ao contexto acadêmico atual, nos perguntamos pelo sentido do produtivismo acadêmico, das métricas de produção que prioritariamente almejam a pontuação do currículo, elegem o veículo de publicização pelo Qualis que apresenta, do produtivismo que fabrica escrita e fomenta equipes ou grupos de escrita, dos eventos eleitos pela potencialidade de turismo agregado, entre tantos fatores que poderíamos listar com uma cultura que se avoluma no universo acadêmico. De outra parte, questionamos acerca do tempo efetivo que atualmente temos para ler, pensar, dialogar e escrever e, de imediato, nos ocorre o questionamento acerca da qualidade de alguns trabalhos que compartilhamos em eventos científicos e publicações e, nesse sentido, perguntamos pela dimensão ética da produção de conhecimento.

Diante disso, observamos que os fundamentos da hermenêutica filosófica advertem para o processo de estudar e pesquisar como um tempo de entrega à leitura atenta e reflexiva dos textos/obras. Como afirma a epígrafe explicitada, temos que "participar" do esforço investigativo colocando-nos em risco de nos metamorfosear: sem esse comparecimento 
"de corpo e alma", transformamo-nos em meros repassadores de informações requentadas.

No ato de estudar, parece mais evidente essa participação, porém, os mecanismos procedimentais da pesquisa podem facilmente nos levar a incorrer em uma atividade sem sujeito. Logo, a autenticidade do diálogo com a tradição que almejamos pelo estudo permite nos transformarmos na relação com nossos objetos/temas de pesquisa no presente e, nessa "fusão de horizontes", podemos perspectivar a emergência do novo.

\section{Estudar e pesquisar presume disciplina intelectual: contribuições para a educação}

Prospectando o tema no horizonte da educação podemos destacar que a abertura é o núcleo da hermenêutica filosófica que se estrutura ao modo de pergunta; essa, por sua vez, é o âmbito desencadeador da compreensão, portanto, da própria aprendizagem. No encalço dessa noção é possível afirmar que a aprendizagem orbita em torno da pergunta, da reflexão, do diálogo. Nesse sentido, a educação se enriquece quando assume o risco da abertura, que por sua vez requer uma postura ético-política, pois num horizonte republicano e democrático, a aposta é sempre na autonomia do sujeito. ${ }^{10}$ Autonomia que se constrói paulatinamente, num processo de ensino e aprendizagem no qual se é convocado a repensar a visão de mundo, qualificar as opiniões e alargar a bagagem artística, filosófica, científica e cultural.

Deste horizonte de compreensão, entendemos que a educação que visa uma formação alargada tem alguns desafios a enfrentar, entre eles, incluir a dimensão da pesquisa como um princípio formativo, um âmbito que fomenta a participação do sujeito no processo de sua própria compreensão das coisas. Outro, diz respeito ao estudo: aprender estudar a partir de algo que se quer entender requer concentração e disciplina (que exige autodeterminação), a mobilização de textos qualificados - aqui destacamos os clássicos a explicitação de conceitos, conteúdos e temas; cercar-se de instrumentos de estudos como dicionários (gerais, específicos), obras clássicas e contemporâneas, revistas qualificadas, documentários e demais materiais disponíveis nas bibliotecas e, também, no ciberespaço.

\footnotetext{
10 Por educação republicana e democrática (ERD), entendemos aquela que se estrutura em torno de um projeto que visa a inclusão, a qualidade, a laicidade e a democracia. Isso significa, uma educação que promova a autonomia do sujeito para sua participação qualificada no processo de constituição social que visa um projeto de mundo comum.
} 
Aprender estudar e pesquisar é, antes de mais nada, um ato de humildade: admite-se que temos algo a aprender com alguém;

[...] aprender com base no já aprendido por quem 'veio antes', aliado à necessidade de fazê-lo em perspectiva própria, no sentido de tomar esse aprendizado como novo para cada aprendente, parece ser a questão central da educação (FENSTERSEIFER; BOUFLEUER, 2011, p. 390).

Nesse sentido, empreender a análise de uma obra/pensamento, exige de nós a postura ético-política de respeito ao autor, em contraposição a postura que busca "destruir o autor", perseguindo contradições, falhas ou concepções, tomando isso por crítica. De nosso horizonte de compreensão, a crítica se faz justamente na medida em que se compreende a obra/pensamento e, partir disso, hermeneuticamente, se atualizam os sentidos do texto. Assim, a crítica é ético-política na medida em que reconhece a finitude e a potencialidade da obra/pensamento.

Contudo, aprender estudar e pesquisar requer uma disciplina intelectual, que necessita ser constituída desde a infância. Isso significa dizer que a escola não só ensina conteúdos conceituais e valores - expressos em habilidade e competências - como também transmite uma herança cultural que the é própria, que é seu fundamento primeiro: instrução e formação. Para Fensterseifer e Boufleuer (2011, p. 391),

A questão da disciplina intelectual pode muito bem ser situada a partir do princípio que rege a própria vida humana: cada ganho tem seu preço; cada vitória tem seu custo; à coluna dos créditos sempre corresponde uma coluna dos débitos.

A autonomia que a educação proporciona a partir da herança que transmite se faz através da justa medida entre coerção e liberdade, e sendo assim, aprender requer disposição (desejo) e mobilização: "[...] todo aprendizado é um ganho que, por sua vez, tem um custo; o custo do esforço, do empenho, da determinação. É o que chamamos de disciplina intelectual" (FENSTERSEIFER; BOUFLEUER, 2011, p. 391). Nesta acepção, a disciplina intelectual requer o cultivo de um hábito, que é uma dimensão fundamental dos que estudam, dos que empreendem um projeto de compreensão, porque para compreender em profundidade um pensador, uma teoria ou um contexto sócio-histórico é preciso, antes de tudo, a capacidade de entediar-se.

\section{Considerações finais}

A pergunta movimenta o sujeito para fora de si mesmo e, por isso, ser capaz de formular uma pergunta autêntica é, por sua vez, empreender uma aventura de autoeducação. Estudar e pesquisar abrem essa possibilidade cocriativa uma vez que põe em suspense o 
que já se sabe, permitindo que permanentemente algo seja ressignificado. Nisso, reside uma possibilidade de acesso à alteridade, aspecto fundamental da formação humana que, antes de mais nada, se faz em relação ao outro.

Por fim, estudar pode ser um investimento pessoal e também cultural, produzido a partir da percepção de que algo nos falta no horizonte da nossa própria humanização. A educação participa desse processo auto formativo na medida em que contribui na produção dessa falta, bem como, na indicação de caminhos a seguir... O estudo, além de abrir diferentes janelas, desenvolve competências argumentativas, propositivas, decisórias e autointerrogativas (BRAYNER, 2006), que constituem âmbitos significativos da aprendizagem e da formação em uma educação republicana e democrática, a qual carrega a perfectibilidade e incompletude como dimensões constitutivas.

\section{Referências}

BRAYNER, F. H. Educação popular e "competência" republicana. In: REUNIÃO ANUAL DA ANPED, 29, 2006 - UFPE GT: Educação Popular/n. 06. Anais [...]. Disponível em: file://D:/Usuario/Desktop/COORDENA\%C3\%87\%C3\%830\%20NUCLEO\%20LICENCIATU RA\%20\%202015/textos\%20para\%20grupos\%20de\%20estudos\%20curriculo\%202019/G T06-2189--Int.pdf. Acesso em: 01 out. 2018.

DALBOSCO, A. C. Pesquisa educacional e experiência humana na perspectiva hermenêutica. Cadernos de pesquisa. v.44, n. 154, p. 1028-1051 out./dez. 2014.

DALBOSCO, A. C. Filosofia da educação e formação do sujeito pesquisador: alguns aportes hermenêuticos. In: REUNIÃO NACIONAL DA ANPED. 38, GT17 - Filosofia - trabalho 550. Anais [...]. UFMA, São Luiz do Maranhão, 2017.

FENSTERSEIFER, P.; BOUfLEUER, J. P. Conhecimento e crítica: em busca de uma fundamentação não metafisica. In: MÜHL, E. H.; GOMES, L. R.; ZUIN, A. A. S. (Orgs.). Teoria, crítica, filosofia e educação. Homenagem a Pedro L. Goergen. Coedição Passo Fundo: Editora da Universidade de Passo Fundo; Maringá: Editora da Universidade Estadual de Maringá, 2014.

- Disciplina intelectual. Algumas reflexões a propósito da homenagem a um intelectual. In: BOMBASSARO, C. A.; KUIAVA, E. A. Pensar sensível: homenagem a Jayme Paviani. Caxias do Sul: EDUCS, 2011. p. 387-398. 
GADAMER, H.G. O problema hermenêutico e a ética de Aristóteles. Conferência 4. In: FRUCHON, P. (Org.). O problema da consciência histórica. Tradução Paulo C. D. Estrada. Rio de Janeiro: Fundação Getúlio Vargas, 1998.

- Verdade e método I: traços fundamentais de uma hermenêutica filosófica. Tradução Flávio Paulo Meurer. 3. ed. Petrópolis, RJ: Vozes, 1999.

Verdade e método II: complementos e índices. Tradução: Enio Paulo Giachini. Revisão da tradução Márcia Sá Cavalcante Schuback. 2. ed. Petrópolis, RJ: Vozes, 2004.

JOHANN, M. R.; FENSTERSEIFER, P. E. Estudo e pesquisa: o inflacionamento informativo e o deflacionamento compreensivo. In: FUCHS, C.; SCHWENGBER, I. L.; SCHUTZ, J. A. (Orgs). Educação em debate: cercanias da pesquisa. São Leopoldo: Oikos, 2018. p.1223.

JOHANN, M. R. Linguagem, arte e educação ético-estética em perspectiva hermenêutica filosófica. 2015. Tese (Doutorado em Educação e Ciências) Universidade Regional do Noroeste do Estado do Rio Grande do Sul, Ijuí, RS, 2015.

LARROSA, J. B. Educação, Linguagem e Diferença. In: SEMINÁRIO EM EDUCAÇÃO NAS CIÊNCIAS - PPGEC UNIJUÍ. Anais [...]. Ijuí-RS. Fonte oral, 2002.

LAWN, C. Compreender Gadamer. Petrópolis, RJ: Vozes, 2007. (Série Compreender).

ROHDEN, L. Hermenêutica filosófica. Entre a linguagem da experiência e a experiência da linguagem. São Leopoldo: Editora UNISINOS, 2002.

ROHDEN, L. Hermenêutica filosófica: entre Heidegger e Gadamer! Revista Natureza Humana, v. 14, n. 2, São Paulo, 2012. Disponível em: http://pepsic.bvsalud.org/scielo.php?pid=S1517-

24302012000200002\&script=sci_arttext. Acesso em: 5 mar. 2018.

SCHMIDT, L. K. Hermenêutica. Tradução Fábio Ribeiro. 2. ed. Petrópolis, RJ: Vozes, 2013. (Série Pensamento Moderno).

SCHNEIDER, P. R. À luz do passado. In: Aula inaugural do Programa de PósGraduação em Educação nas Ciências - PPGEC UNIJUÍ, Ijuí/RS. Fonte oral, 2018.

WADDINGTON, C.B.G. Tradição, conhecimento e interpretação. Revista Tempo Brasileiro. Rio de Janeiro, n. 148, p. 169-185, jan./mar. 2002. 
'Professora do Departamento de Humanidades e Educação da Universidade Regional do Noroeste do Estado do Rio Grande do Sul.

\section{Como citar esse artigo:}

JOHANN, Maria Regina Regina. Estudo, pesquisa e produção do conhecimento no horizonte hermenêutico-filosófico. Revista Digital do LAV, Santa Maria: UFSM, v. 11, n. 3, p. 82 97, set./dez. 2018. 